Brit. J. industr. Med., 1960, 17, 187.

\title{
PHOSGENE POISONING CAUSED BY THE USE OF CHEMICAL PAINT REMOVERS CONTAINING METHYLENE CHLORIDE IN ILL-VENTILATED ROOMS HEATED BY KEROSENE STOVES
}

\author{
BY \\ W. B. GERRITSEN and C. H. BUSCHMANN \\ From the Central Service of the Labour Inspectorate, The Hague, Holland
}

(RECEIVED FOR PUBLICATION JANUARY 8, 1960)

Two cases resembling poisoning by phosgene following the use of a paint remover containing methylene chloride in ill-ventilated rooms heated by an oil stove are described. Experiments carried out under similar conditions demonstrated the production of phosgene in toxic concentrations. The potential hazards from non-inflammable solvents are discussed.

The use of chemical paint removers (CPR) is increasing and it seems likely that they may be used more extensively in the home by "Do-it-yourself" enthusiasts. The widely used non-inflammable types contain chlorinated hydrocarbons as the main solvent of which methylene chloride $\mathrm{CH}_{2} \mathrm{Cl}_{2}$ is probably the most common. The toxic hazards from the vapour of the solvents themselves appear not to be great as few cases of poisoning have been reported (Schütz, 1936). However, another potential hazard, namely the production of phosgene has been drawn to our attention by two cases of poisoning, one of which was fatal. Experiments were carried out to check that the formation of phosgene can in fact take place under these conditions.

\section{Case Histories}

Case 1.-A 52-year-old painter removed the paint from the woodwork in a small room on a winter morning by applying a non-inflammable chemical paint remover. It was very cold and he kept the windows closed and used a portable kerosene stove to heat the room. The stove was not connected to a chimney. Soon after starting work he felt uncomfortable, noticing, as he stated afterwards, a burning sensation in his throat. Nevertheless he went on with the job which he finished at noon. On his way home he became aware of a feeling of tightness in the chest. After lunch an increased feeling of oppression made him call his physician. Auscultation revealed râles widespread over both lung fields and a diagnosis was made of influenzal bronchiolitis. At 6 p.m. the physician was again called. He found the patient extremely dyspnoeic and cyanotic and referred him to hospital. A few hours after arrival there the man died notwithstanding every therapeutic effort. The diagnosis was influenzal pneumonia, oedema of the lungs, and cardiac decompensation. The necropsy seemed to confirm this diagnosis as extensive degenerative changes were found in the epithelium of the trachea, bronchi and bronchioli together with haemorrhagic oedematous focal pneumonia. Bacteriological and virological investigations were not performed.

Case 2.-A 38-year-old woman in the seventh month of pregnancy treated a cupboard with a non-inflammable CPR one afternoon. The work was performed in a cellar and took about three hours. The cellar was heated by a portable kerosene stove. In the course of the evening she noted an increasing feeling of tightness in the chest; once or twice she expectorated some blood-stained sputum. A physician did not consider the symptoms alarming and prescribed a sedative. Next morning, after an uncomfortable night, she felt much worse and called the physician again. The symptoms were dyspnoea and cyanosis; the pulse rate was 120 , the temperature $101^{\circ} \mathrm{F}$. The doctor sent her at once to hospital where a chest radiograph showed diffuse opacities similar to those seen in cases of pulmonary oedema. Therapy included oxygen, antibiotics, and cortisone. The patient recovered and was discharged after eight days, though not all radiographic abnormalities had disappeared. Two months later she gave birth to a healthy child.

\section{Experimental}

The CPR used by Case 1 was found to contain $92 \%$ of volatile solvent consisting almost entirely of methylene chloride with small amounts of ethanol and trichloroethylene. 
In each test a painted surface (wood) of 0.3 square metres was treated with approximately $50 \mathrm{~g}$. of a CPR having the same composition as the one used by the deceased. Immediately after treatment the object was placed in a large cupboard $6 \mathrm{~m} .{ }^{3}$. In the cupboard the kerosene stove used in the actual case was kept burning during each test. The door of the cupboard was kept tightly closed during each test and samples of the air were drawn from inside through a glass tube which had been inserted through a hole in the door at a height of $1.3 \mathrm{~m}$. As the speed of decomposition and the relative amounts of the decomposition products formed may vary within wide limits (depending on the chlorinated hydrocarbon present and the circumstances under which the decomposition takes place (Little, 1955; Nuckolls, 1933)), we have tried to simulate the actual circumstances as closely as possible in our tests.

\section{Methods of Analysis}

In our investigation we used two different methods, one was developed by the British Department of Scientific and Industrial Research (1939) and the other by collaborators of the US Bureau of Mines and the US National Board of Fire Underwriters (Matuszak, 1934). Both methods were only slightly modified.

Method 1.-The only difference from the D.S.I.R. method consisted of the use of a centrifugal air pump with a constant rate of $11 . / \mathrm{min}$. instead of the handpump. The sampling time varied from $\frac{1}{4}$ to several minutes. The colour of the test paper was then compared with the standards and the phosgene concentration calculated.

Method 2. $-100 \mathrm{ml}$. of an aqueous $0.5 \mathrm{~N}$ solution of $\mathrm{KOH}$ contained in a spiral gas bubbler was used as the absorbing medium. Air was drawn through at a rate of $0 \cdot 2-0 \cdot 51 . / \mathrm{min}$. for $20 \mathrm{~min}$. The contents of the bubbler were then neutralized with nitric acid and the chloride content was determined using Mohr's method.

In both methods a tube containing pumice granules impregnated with a solution of potassium iodide and sodium thiosulphate was used to remove $\mathrm{HCl}$ and $\mathbf{C l}_{\mathbf{2}}$. The efficiency of the pumice granules was first tested by drawing through the tube a mixture of $\mathrm{HCl}$ and $\mathrm{Cl}_{2}$ in air. This mixture was prepared by passing the air through a series of three bubblers containing $\mathrm{HCl}(\mathrm{S} . \mathrm{G} .1 \cdot 09)$, concentrated sodium hypochlorite solution and $\mathrm{HCl}$ (S. G. 1-09). The air leaving the tube containing the pumice granules was then analysed as in method 2 . No chloride was found.

The methylene chloride itself is not retained by the impregnated pumice granules and it leaves the tube unaltered. This will not interfere with method 1. In method 2, however, some interference might be expected (Matuszak, 1934).

This was checked by passing 301 . of air containing $50 \mathrm{~g}$. of methylene chloride per $\mathrm{m}^{3}$ through the bubbler used in method 2. The apparent phosgene concentration found at this extremely high concentration was negligible ( $+5 \mathrm{mg} . / \mathrm{m}^{3}$ ) as compared with the amounts of phosgene actually found.

Finally, the methylene chloride concentration in the cupboard was determined under the same test conditions as described above, without however, burning the kerosene stove. The temperature inside the cupboard must have been considerably lower, resulting in a lower evaporation rate of the solvent. In this test methylene chloride was determined by total decomposition in a quartz tube using platinum as a catalyst at $900^{\circ} \mathrm{C}$. as described by Jacobs (1949).

\section{Results}

The quantities of phosgene in the air of the cupboards determined by Method 1 are given in the Table.

TABLE

CONCENTRATION OF PHOSGENE IN A CUPBOARD IN WHICH A KEROSENE STOVE WAS BURNING, ESTIMATED AT DIFFERENT TIMES AFTER EXPOSING A WOODEN SURFACE TO WHICH A CHEMICAL PAINT REMOVER CONTAINING METHYLENE CHLORIDE HAD BEEN APPLIED.

\begin{tabular}{|c|c|c|}
\hline \multirow{2}{*}{$\underset{\text { (min.) }}{\text { Time after start }}$} & \multicolumn{2}{|c|}{ Phosgene } \\
\hline & $\mathrm{mg} . / \mathrm{m}^{3}$ & p.p.m. \\
\hline $\begin{array}{c}\text { Experiment } 1 . \\
11 \\
19 \\
26 \\
54\end{array}$ & $\begin{array}{l}\text { applied.) } \\
140 \\
200 \\
300 \\
55\end{array}$ & $\begin{array}{l}32 \\
45 \\
68 \\
12\end{array}$ \\
\hline $\begin{array}{c}\text { Experiment } 2 . \quad \text { (54. } \\
3 \\
6 \\
9 \\
12 \\
26 \\
37 \\
42 \\
67\end{array}$ & $\begin{array}{c}\text { applied.) } \\
70 \\
140 \\
200 \\
560 \\
335 \\
150 \\
130 \\
35\end{array}$ & $\begin{array}{r}16 \\
32 \\
45 \\
128 \\
77 \\
34 \\
30 \\
8\end{array}$ \\
\hline
\end{tabular}

In two other experiments phosgene (estimated by Method 2) and methylene chloride were determined during a continuous period from the start of the experiment in which about $50 \mathrm{~g}$. of CPR were applied. The concentrations of phosgene were 750 and $760 \mathrm{mg} . / \mathrm{m} .{ }^{3}$ in two experiments and methylene chloride 700 and $1,300 \mathrm{mg} . / \mathrm{m}^{3}$ in two other tests.

\section{Discussion}

The experiments which we conducted show clearly that methylene chloride is decomposed at a high rate-phosgene being the main decomposition product-when the vapours are present in a closed cupboard in which a portable kerosene stove is burning. This is rather surprising as other investigations have shown that in different circumstances (decomposition by hot surfaces) the decomposition rate of methylene chloride is very low, much lower 
in fact than that of other chlorinated hydrocarbons. Moreover, the production of phosgene has always been found to be low in comparison with the production of hydrogen chloride, and chlorine (Little, 1955; Nuckolls, 1933).

The findings of our experiments may possibly be explained by the fact that the methylene chloride vapour is mixed with the air used for the combustion of kerosene in the stove. The vapour thus passes through the flames, coming into close contact with carbon monoxide at high temperatures. Any chlorine formed by decomposition may under these conditions react with carbon monoxide and form phosgene. Indeed the passing of chlorine together with carbon monoxide over carbon black actually is one of the processes by which phosgene is produced (Ullmann, 1929). Moreover the combustion products of the stove could not escape from the room and were being constantly recirculated, thus gradually increasing the amount of decomposition products present. Of course, our testing conditions were severe as we used a closed cupboard of only $6 \mathrm{~m} .^{3}$ capacity. Under these conditions lethal phosgene concentrations were formed within five to 10 minutes.

Our case histories indicate, however, that under conditions such as may be encountered in practice in small, ill-ventilated rooms, lethal or dangerous phosgene concentrations can be formed within a period as short as three hours.

Preventive Measures.-As the use of non-inflammable CPR under the above-mentioned con- ditions constitutes a real danger, preventive measures are of the utmost importance.

Combustion stoves which do not have a proper connexion to a chimney should never be used in rooms where the CPR is being employed. With an electric stove the danger seems to be much less, but even then small amounts of phosgene may be formed together with the other decomposition products of the solvents. Heating by electric stoves therefore appears to be safe only when the room is well ventilated. In any case adequate ventilation is always necessary when using CPR in small rooms as the solvent vapours are in themselves toxic.

One aspect which constitutes a difficulty in promoting the safe use of non-inflammable CPR may finally be mentioned. It lies in the fact that the indication "non-inflammable" which is often printed on the label of the container suggests that its contents can safely be used in the vicinity of an open fire or hot surface. As this is one of the principal reasons why people select the non-inflammable CPR it will not be easy to persuade the manufacturers to qualify this statement on the label.

\section{REFERENCES}

Dept. of Scientific and Industrial Research. Methods for the detection of toxic gases in Industry. Leaflet No. 8: Phosgene. 1939. H.M.S.O., London.

Jacobs, M. B. (1949). The Analytical Chemistry of Industrial Poisons, Hazards and Solvents, 2nd ed. Interscience, New York.

Little, J. (1955). Brit. J. industr. Med., 12, 304.

Matuszak, M. P. (1934). Industr. Engng Chem. (Anal. Ed.), 6, 374. Nuckolls A.M. (1933). Report on the Comparative Life, Fire and Explosion Hazard of Common Refrigerants. National Board of plosion Hazard of Common Refr

Fire Underwriters, New York.
Schütz, H. (1936). Arch. Gewerbepath. Gewerbehyg., 7, 452.

Ullmann, F. (1929). Enzyklopädie der technische Chemie, 2nd ed. Vol. 3, p. 351. Urban and Schwarzenberg, Berlin. 